\title{
Anatomy of the Greater Occipital Nerve: Implications in Posterior Fossa Approaches.
}

Gaetan LAINE ( $\square$ gaetan.laine@neurochirurgie.fr)

CHU Bordeaux GH Pellegrin: Centre Hospitalier Universitaire de Bordeaux Groupe hospitalier Pellegrin https://orcid.org/0000-0002-4825-8030

\section{Vincent JECKO}

CHU Bordeaux GH Pellegrin: Centre Hospitalier Universitaire de Bordeaux Groupe hospitalier Pellegrin

Thomas WAVASSEUR

CHU Bordeaux GH Pellegrin: Centre Hospitalier Universitaire de Bordeaux Groupe hospitalier Pellegrin

\section{Edouard GIMBERT}

CHU Bordeaux GH Pellegrin: Centre Hospitalier Universitaire de Bordeaux Groupe hospitalier Pellegrin Jean Rodolphe VIGNES

CHU Bordeaux GH Pellegrin: Centre Hospitalier Universitaire de Bordeaux Groupe hospitalier Pellegrin Dominique LIGUORO

CHU Bordeaux GH Pellegrin: Centre Hospitalier Universitaire de Bordeaux Groupe hospitalier Pellegrin

\section{Research Article}

Keywords: Greater occipital nerve, Posterior fossa approach, Occipital neuralgia, Post-operative pain, Surgical technique, Anatomy

Posted Date: September 28th, 2021

DOl: https://doi.org/10.21203/rs.3.rs-858885/v1

License: (c) (i) This work is licensed under a Creative Commons Attribution 4.0 International License. Read Full License

Version of Record: A version of this preprint was published at Surgical and Radiologic Anatomy on February 24th, 2022. See the published version at https://doi.org/10.1007/s00276-022-02906-X. 


\section{Abstract}

Purpose: Because of its superficial location in the dorsal regions of the scalp, the greater occipital nerve (GON) can be injured during neurosurgical procedures, resulting in post-operative pain and postural disturbances. The aim of this work is to specify the course of the GON and how its injuries can be avoided while performing posterior fossa approaches.

Methods: This study was carried out at the department of anatomy in Bordeaux University. 4 specimens were dissected to study the GON course. Posterior fossa approaches (midline suboccipital, paramedian suboccipital, retrosigmoid and petrosal) were performed on 4 other specimens in order to assess potential risks of GON injuries.

Results: The GON runs around the obliquus capitis inferior (100\%), crosses the semispinalis capitis $(100 \%)$ and the trapezius (75\%) or its aponeurosis (25\%). Direct GON injuries can be seen in paramedian suboccipital approaches. Stretching of the GON can occur in midline suboccipital and paramedian suboccipital approaches. We found no evidence of direct or indirect GON injury in retrosigmoid or petrosal approaches.

Conclusion: Our study provides interesting data regarding the risk GON injury in posterior fossa approaches. Direct GON injuries in paramedian suboccipital approaches can be avoided with careful dissection. Placing retractors in contact with the periosteum and performing a minimal retraction may help to avoid excessive GON stretching in midline suboccipital and paramedian suboccipital approaches. Furthermore, incision for retrosigmoid approaches should be as lateral as possible and not too caudal. Finally, avoiding extreme patient positioning reduces the risk of GON stretching in all approaches.

\section{Introduction}

The greater occipital nerve (GON), also known as Arnold's nerve, arises from the dorsal ramus of the second spinal nerve (C2) [1-6]. Its main function consists in the sensitive innervation of the dorsal part of the scalp, together with the lesser occipital nerve, the third occipital nerve, and sometimes the greater auricular nerve $[2,7]$.

Its course in the dorsal regions of the neck is subject to intra- and inter-individual variability [8]. After its emergence, it goes towards the obliquus capitis inferior and runs around this muscle in the majority of cases $[1-3,9,10]$. Then it runs through the semi spinalis capitis, crossing its muscular fibers at about 10$15 \mathrm{~mm}$ lateral to the midline $[4,8,10,11]$. The crossing of this muscle by the GON is not constant, as highlighted by the work of Bovim et al (90\%), Tubbs et al (90\%), and Ducic et al (98.5\%) [8-10]. It finally goes to the trapezius, with most of the works suggesting that the GON crosses its aponeurosis more often than the muscle itself $[3,9,10,12]$. This penetration point is situated at about $23,24 \mathrm{~mm}$ lateral from the midline $[10,13]$. 
The GON becomes subcutaneous just after its emergence at the superficial part of the trapezius. Generally, this point is located just below the superior nuchal line [3] and about 5 to $28 \mathrm{~mm}$ lateral to the midline [12]. Caudal to the superior nuchal line, it begins its division into terminal branches, with a high anatomical variability [12]. Medial branches innervate the occipital skin, intermediate branches run cranially to innervate the vertex, and lateral branches innervate skin next to the mastoid process [3]. The GON is accompanied in its superficial course by the occipital artery (OA) [5]. This artery appears to be lateral to the GON in the majority of cases [5, 14], but can sometimes be found medial to it [1], surrounded by the GON [12], or even be in a common fascia [12].

Clinical symptoms associated with GON injury frequently consist of neuralgic pain in the area of the affected nerve. This is most often referred to occipital neuralgia, but it can be called by many other names in the literature, such as Arnold's neuralgia, cervical migraine, or cervicogenic headache [15]. The International Headache Society (IHS) describes occipital neuralgia as a paroxysmal stabbing pain in the sensory territory distributed by the greater occipital nerve, lesser occipital nerve, or third occipital nerve, sometimes accompanied by dysesthesias in the affected areas [16]. However, symptoms are not limited to neuralgic pain. Indeed, because of the rich proprioceptive afferents of the upper cervical muscles and their relationship with the vestibular nuclei [17], patients with occipital neuralgia may also present vestibular disorders disabling postural instability [18].

Many neurosurgical approaches to the posterior cranial fossa are described. Those can be lateral (subtemporal approach, petrosal approach), posterolateral (retrosigmoid approach, far lateral approach, paramedian suboccipital approach) or located on the midline (midline suboccipital approach) [19]. Subtemporal approaches are located anterior to the ear, so that the GON might not be injured. While performing the other ones, surgeons might injure the GON because of its superficial location in the dorsal regions of the scalp. The development of a post-operative GON injury is favored by direct damage to the occipital nerves during surgery, compression of the nerve in postoperative scar tissue or formation of post-traumatic scar neuromas $[20,21]$. Since occipital neuralgia is a source of significant post-operative morbidity and has an impact on quality of life [20,21], it must be well known and prevented during surgical approaches to the posterior cranial fossa, which are common practice in neurosurgery.

The aim of this work is to specify the anatomical relationships of the GON based on an anatomical study carried out on cadaveric specimen, to determine how its injuries can be avoided while performing posterior fossa approaches.

\section{Materials And Methods}

\section{Study Design}

This study was carried out at the department of anatomy in Bordeaux University. 8 specimens of head and neck embalmed with $10 \%$ formalin were dissected. Of these, 2 specimens were previously injected with red-colored neoprene latex into the external carotid system in order to visualize OA. 
We first performed a dissection of the GON among its course to understand its anatomical relationships with surrounding structures. Then we performed common posterior fossa approaches with an assessment of potential injuries to the GON

\section{Dissection of the GON}

4 specimens were dissected. Among them, 2 specimens were previously injected with red colored neoprene latex into the external carotid system.

To locate the course of the GON, 2 specimens were placed in the prone position. After shaving the dorsal regions of the head and neck, a midline incision was made from $3 \mathrm{~cm}$ above the external occipital protuberance (EOP) to the spinous process of the 7th cervical vertebra (C7). This incision was completed by 2 tangential incisions at the ends of this first incision, for approximately $7 \mathrm{~cm}$ laterally (Fig. 1.a). In one cadaver, the GON was followed in depth through the muscles of the neck to its apparent origin opposite the atlanto-axial intervertebral space. In the other cadaver, a median dissection of neck muscles was performed until the apparent origin of the GON was found. Its course was then followed superficially into the dorsal regions of the neck.

The relationship between the GON and the OA was studied more specifically using the 2 injected specimens. Those were placed in the prone position. Incisions were made using the description of Won et al in order to find both nerve and artery [14]. We drew a line from the mastoid process to the EOP. This line was then divided into 3 equally sized segments. A line perpendicular to the midline and passing through the junction between the medial and middle thirds of this segment was drawn. The incision made was on this line, $3 \mathrm{~cm}$ cranial and caudal crossing the line connecting the mastoid process to the EOP. The incision was extended laterally and medially by $2 \mathrm{~cm}$ to expose and retract the subcutaneous tissues (Fig. 1.b).

\section{Posterior fossa approaches}

4 specimens were dissected and 4 common approaches were studied in our work: the midline suboccipital approach, the paramedian suboccipital approach, the retrosigmoid approach and the transpetrosal approach (Fig. 2).

Midline suboccipital approach: incision extended along the midline from $1 \mathrm{~cm}$ above the EOP to the first palpable cervical vertebral spinous process (mainly C7). Dissection of the subcutaneous layer was performed along the midline, and muscle dissection along the nuchal ligament until it reached the occipital bone. The periosteum was then roughened laterally, displacing the muscle masses with it. The dorsal arch of the atlas was also exposed. In order to locate the GON, 2 paramedian incisions were also made. These extended laterally $1-5 \mathrm{~cm}$ from the midline incision.

Paramedian suboccipital approach: A segment was drawn between the tip of the mastoid process and the EOP. Incision extended parallel to the midline, through a point passing in the middle of this segment, for approximately $8 \mathrm{~cm}$ height with a proportion of $1 / 3$ length cranial to this point and $2 / 3$ length caudal 
to it. Dissection was performed trans-muscularly, until the occipital bone was reached. The periosteum was then roughened laterally, displacing the muscle masses with it. Occipital bone was thus exposed. In order to study the risk of nerve damage following this approach, we then made a midline incision and dissected the subcutaneous layer laterally until the paramedian incision was reached.

Retrosigmoid approach: Anatomical landmarks were the tip of the mastoid and the helix. An incision was located one fingerbreadth dorsal to the mastoid tip, and extended from the mastoid tip to the helix in a slightly concave forward path. The incision was made until bony contact was felt. The periosteum was then roughened laterally, displacing the muscle masses with it. Occipital bone was thus exposed. In order to determine the risk of GON injury during this approach, a paramedian incision was made starting laterally $1 \mathrm{~cm}$ from the midline and extending up to $2 \mathrm{~cm}$ medial to the approach. The nerve was then dissected until we found its lateral crossing point opposite the obliquus capitis inferior.

Transpetrosal approach: A retroauricular inverted C-shaped incision was performed. It started at the cranial part of the ear, one fingerbreadth above the helix, extended dorsally to pass 3 fingerbreadths dorsal to the auricle and then ended opposite the auricle. Incision was performed through the depth of the subcutaneous layers until feeling bony contact. The remaining muscle was roughened to expose a very large retroauricular bony surface. A paramedian incision in the form of a $5 \mathrm{~cm}$ long square was then performed. It extended laterally from 1 to $6 \mathrm{~cm}$ from the midline, with the most cranial point located at the same level as the most cranial point of the incision. The subcutaneous layers within this square were dissected to locate the GON.

\section{Data Collection}

The course of the GON was assessed each time it crossed a neighboring muscular element (obliquus capitis inferior, semispinalis capitis and trapezius). Lateral distances from the midline and craniocaudal distances from the EOP were measured with a ruler.

Concerning its relationships with the OA, parameters studied were the position of the GON and OA, the distance between those 2 entities, the existence of a possible common fascia and the way they cross.

Assessment of direct GON injury while performing posterior fossa approaches was performed by measuring the distance between the GON and the incision path.

Assessment of indirect GON injury was performed using retractors and threads in the different layers severed by the incision. The severity of GON deformation by either retractors or threads was considered a good indicator for indirect nerve injury. Tractions in the lateral or medial direction with threads were all performed with the same gravitational force ( $5 \mathrm{~kg}$ weight attached to the wire and suspended in the air).

\section{Ethics approval}

Given the documents at its disposal, the Research Ethics Committee of Bordeaux issued a favorable opinion for the publication of this research (GP-CE2021-18) 


\section{Results}

No previous surgery or injuries in the cranio-cervical regions were found in the specimens dissected in our study.

\section{Dissection of the GON (tables 1 and 2)}

The GON could be found and dissected bilaterally in the 2 specimens used to study its course ( 4 greater occipital nerves). The GON and AO could be individualized bilaterally in the 2 specimens dissected to study their relationship (4 greater occipital nerves and 4 occipital arteries).

The emergence point of the GON was located at the level of the atlantoaxial intervertebral space, at an average distance of $18 \mathrm{~mm}$ from the midline ( $\mathrm{min}: 17 \mathrm{~mm}$ - max: $19 \mathrm{~mm}$ ). This distance appeared symmetrical in only one of the two subjects studied.

After leaving the intervertebral space, the GON ran laterally, caudal to obliquus capitis inferior. In all specimens (4/4), the nerve went around this muscle without crossing it. The nerve then ran dorsally to the semispinalis capitis, which it crossed in every specimen (4/4). The last muscular connection found concerned the trapezius muscle. The GON crossed the muscle itself in $75 \%(3 / 4)$, and its aponeurosis in $25 \%$ of cases $(1 / 4)$.

Subcutaneous emergence of the GON was found in all subjects with an average of $22.75 \mathrm{~mm}$ (min: $17 \mathrm{~mm}$, max: $27 \mathrm{~mm}$ ) from the midline laterally, and an average of $18 \mathrm{~mm}$ ( $\mathrm{min}: 15 \mathrm{~mm}$, max: $21 \mathrm{~mm}$ ) caudal to the EOP. Thereafter, the nerve gave multiple branches to innervate the dorsal and cranial cervical regions.

The GON appeared lateral to the OA in 2 specimens (50\%), while it was medial to it in the other $2(50 \%)$. In 3 cases $(75 \%)$, the GON only crossed the AO, whereas in 1 case (25\%), the nerve and artery travelled together in the subcutaneous layer of the dorsal cervical region (Fig. 3). None of the 4 dissections revealed the presence of a common fascia between the GON and the OA.

\section{Posterior fossa approaches (table 3)}

The GON was found and dissected in the 4 specimens used (8 greater occipital nerves). Thus, its relationship with the incision path could be studied for all the approaches performed.

\section{Midline suboccipital approach}

No nerve fibers belonging to the GON were found or severed during this approach. In fact, the nerve was found at a most medial distance of $14 \mathrm{~mm}$ on the right side and $15 \mathrm{~mm}$ on the left side.

Using retractors at the cranial and caudal sides of the incision, we noticed that a deformation of the nerve appeared as soon as we performed sufficient spacing to expose the occipital bone. The results of the various traction performed with the threads were similar on both sides of the study. Only the traction 
performed with the threads placed in the muscles and on the periosteum allowed sufficient exposure of the occipital bone for further surgery. When comparing the deformation and lateral translation of the GON following maximum traction on the threads opposite the periosteum and the muscle masses, we noted that this deformation appeared to be greater with the wires placed in the muscles (Fig. 4). This was found bilaterally.

\section{Paramedian suboccipital approach}

Several nerve nets belonging to the lesser occipital nerve were transected along the path of the approach. No GON injury was found. However, one of its branches was found $6 \mathrm{~mm}$ from the approach (Fig. 5)

When comparing the nerve strain exerted with equal traction on the periosteum and in the muscles, we found that the strain appeared to be less when using the traction threads opposite the periosteum.

\section{Retrosigmoid approach}

None of the GON fibers were severed during this surgical approach, with the most lateral point of the GON found at $29 \mathrm{~mm}$ from the incision (Fig. 6).

No significant nerve stretch was found after traction on the various threads apposed along the approach, either at the level of the subcutaneous division branch of the nerve or opposite the inferior oblique muscle bypass.

\section{Transpetrosal approach}

No GON fibers were severed during the transpetrosal approach, with the most lateral point of the GON found at $24 \mathrm{~mm}$ from the incision path (Fig. 7).

No retractors were placed towards the GON in this surgical approach, as no retraction towards the midline is required in this surgical approach.

\section{Discussion}

Neurosurgical approaches perform close to the occipital nerves are more likely to injure the GON and cause postoperative cranial pain $[22,23]$. Some of these complications seem to be avoidable by good knowledge of the nerve anatomy of this region, careful positioning of the patient in the operating room, modification of the incision (risk of direct nerve damage) or modification of retractors placement (risk of indirect nerve damage).

The course of the GON within the dorsal cranio-cervical regions has been described in multiple anatomical studies $[1-3,5,8-12]$. As suggested by both the literature and our study, its course is relatively constant within the different muscular layers of this region. Conversely, the GON becomes subcutaneous after it crosses the trapezius, whose penetration location is variable. This anatomical inconsistency is confirmed by our results: even if most of the works in the literature stipulate that the 
nerve crosses the aponeurosis of the trapezius muscle rather than the muscle itself $[8-10,12,14]$, our data show a muscle crossing in most of the cases $(75 \%)$. The location of the exit point towards the subcutaneous region found in our study is consistent with the data in the literature [12]. However, the inter-individual variations observed in our dissections $(10 \mathrm{~mm}$ variation from the midline, $6 \mathrm{~mm}$ variation caudal to the EOP) reinforce the fact that the subcutaneous part of the nerve course is subject to anatomical variability. We also found a close anatomical relationship between the GON and the OA, as described in the literature $[1,5,12,14]$. The contribution of this anatomical knowledge allows us to understand that there is an increased risk of injury to the greater occipital nerve in the case of an approach starting with an incision situated between 1 and $4 \mathrm{~cm}$ lateral to the midline. However, if this type of approach is performed, careful dissection of the subcutaneous tissue will allow the identification of the GON, whose point of emergence is situated below the nuchal line. This identification will be facilitated by the identification of the $O A$.

Patient installation and positioning in the operating room also seems to influence the risk of developing postoperative occipital neuralgia. Four types of positioning are classically described for posterior fossa approaches [24] : prone position, lateral decubitus, supine position with head rotation, and sitting position, the latter being rarely used in current practice. Dynamic variation of the course of the GON during neck movements showed that extension of the neck do not affect tension on this nerve [4]. Conversely, head flexion movements appear to stretch the nerve between the obliquus capitis inferior and the semi spinalis capitis [4]. Rotational movements of the head cause a stretching of the contralateral C2 root [4]. Based on those considerations, there are a risk of GON injuries in the prone position and more specifically in the Concorde position (due to extreme head flexion) and in supine position with head rotation (due to stretching of controlateral $\mathrm{C} 2$ root).

Based on our results, the GON course and data from the literature [25], a midline approach should not cause direct GON injuries. Conversely, the hypothesis that the GON can be stretched and injured indirectly by the placement of retractors is a matter of debate. Because of its short distance to the midline $(14 \mathrm{~mm})$, we noticed that the use of retractors to expose occipital bone can stretch the GON, thus suggesting that it can be injured indirectly. On the contrary, Sindou and Mertens studied the GON anatomical landmarks and considered that the midline suboccipital approach allows the integrity of this nerve to be respected [25]. Skins incisions for midline suboccipital approach can obviously not be changed. However, our results show that the GON stretching is proportional to the traction force exerted by the retractors. Furthermore, the placement of the retractors under the periosteum decreases the deformity exerted on the GON. Thus, assuming that there is a risk of indirect GON injury in this approach, we recommend placing the retractors under the periosteum and making a minimal retraction, just sufficient to expose the occipital bone.

There are multiple anatomical landmarks for the skin incision of the lateral suboccipital approach. In all cases, it is located between the midline and the retroauricular region and is therefore at risk of crossing the GON. In our study, we did not find any direct lesion of the GON, but its proximity to the incision (6 mm) and its anatomical variability lead us to believe that this risk does exist. Moreover, because of its close 
relationship with the incision path, there is also a risk of indirect GON injury with retractors placement. The risk of developing postoperative occipital neuralgia after surgery with a lateral suboccipital approach is poorly described in the literature. Most of the time, the approach described using the term lateral suboccipital approach is a retrosigmoid approach [26]. According to our results, this approach is nevertheless the most likely to cause GON injuries, and in particular the only one that could directly injure it. To minimize this risk, we recommend careful dissection of the subcutaneous tissue during this surgical approach. We also recommend placing the retractors under the periosteum, and achieving a minimal retraction, just sufficient for bone exposure.

Multiple incisions are described to perform a retrosigmoid approach. The most common are linear incisions medial to the mastoid and C-shaped incisions [27]. Most anatomical studies estimate risk of GON injury in this approach [27-29]. Aihara et al compared a S-shaped incision (where the GON was rarely cut but often stretched and retracted) and a C-shaped incision (where the GON was neither cut nor stretched during retraction) to explain the factors influencing the duration of postoperative headache in patients undergoing retrosigmoid approach for vestibular schwannoma [28]. They found a significantly shorter duration of postoperative headache in C-shaped incisions, suggesting that stretching of this nerve may lead to postoperative pain. Silvermann et al have described modifications to the retrosigmoid approach, including a skin incision that avoids the occipital nerves and a small craniectomy [29]. The combination of these two factors reduces the probability of occipital nerve injury and may help to reduce the incidence of postoperative headaches. According to the data of Sindou and Mertens [25], only a short oblique retromastoid incision (linear or curved), lateral enough to avoid the area where the nerve goes around the obliquus capitis inferior should not damage the GON. Those data seem to be confirmed by the increased risk of neck pain and headache after vestibular schwannoma removal via the retrosigmoid approach compared to the translabyrinthine [22, 23] and subtemporal [23] approaches. In our study, the most lateral point of the GON was $29 \mathrm{~mm}$ from the incision, which leads us to believe that direct injury to the GON is unlikely. Furthermore, no significant stretching of the nerve was found after traction on the various threads apposed along the approach, suggesting a very low risk of indirect nerve injury during the retrosigmoid approach. The discrepancy between our data and the literature seems to be explained by the fact that the incision we made for the retrosigmoid approach is very close to the ear. This is of course depending on the location of the sigmoid sinus. Thus, in order to minimize the risk of damage to the GON during the retrosigmoid approach, we recommend a fairly lateral approach if possible, 1 fingerbreadth medial to the mastoid. This incision should not extend too far caudally to avoid the point where the GON goes around the obliquus capitis inferior.

The semantics of the petrosal approach have been simplified by Miller who divides them into 2 distinct categories [30] : anterior and posterior petrectomy. Due to the preauricular skin incision in case of anterior petrectomy [30], only the posterior petrectomy approach may provide GON injury. For posterior petrectomy, an inverted $\mathrm{J}$-shaped (or C-shaped) incision with a retroauricular starting point is classically performed [30]. In our study, we did not find any risk of injury to the GON with the petrosal approach. It is lateral enough to avoid the nerve, and no retraction towards the nerve is required. Our results are clinically confirmed by literature, where few postoperative neuralgias are found after petrosal approach. This risk 
appears indeed to be less frequent than for retrosimoid approaches [22, 23]. For example, a recent review of the literature lists 3 studies showing no significant difference in terms of pain between the retrosigmoid and trans-labyrinthine approaches and 4 studies showing a lower rate of postoperative headaches in patients who underwent petrosal approaches [31].

Our anatomical study applied to posterior cranial fossa approaches provides interesting data regarding the risk of intraoperative nerve injury. Performing initially a descriptive anatomical study of the GON allowed us to understand its course. The fact that we performed most of the approaches used in current practice and studied their relationship with the GON seems to us to be a methodological strength to meet the aim of our study. Thus, based on our study and the data in the literature, we propose advice to minimize the risk of intraoperative GON injury (table 4).

However, we admit several limitations to our study. First of all, there are multiple causes for postoperative occipital neuralgia, such as irritation of sensitive nerve branches for the occipital dura mater and the venous sinuses [32], neurogenic inflammation by irritation of the trigeminal nerve [22], muscular adhesions with the dura mater in the case of craniectomy [22,26], muscular damage during the surgical approach [22] or muscular tension due to intraoperative positioning [22]. These different causes have not been considered in our work and may act as confounding factors. In addition, the GON course presents an inter- and intra-individual variability, and we only performed every approach twice. Similarly, we did not study the dynamic variations of the GON related to the positioning of the patient in the operating room. Our protocol for identifying the risk of nerve damage appears to be rigorous: traction was performed in the direction of the nerve, with an identical force each time. On the other hand, the assessment of the neurological risk seems to us to be more approximate, as it was only assessed on the deformation and stretching of the nerve. We also believe that this deformation may be overestimated, since dissection of the nerve frees it from its subcutaneous and muscular adhesions, thus favoring its mobility. Finally, the absence of the possibility of revealing clinical damage felt by the patient prevents us from estimating the clinical translation of our suppositions.

\section{Conclusion}

Our anatomy study provides interesting data regarding the risk of intraoperative GON injury in the posterior fossa approach. Direct GON injuries can appear while performing paramedian suboccipital approaches and can be avoided with careful dissection of the subcutaneous and muscular layers. Indirect GON injuries are likely to appear in midline suboccipital, paramedian suboccipital approaches and can appear in retrosigmoid approaches. We recommend placing retractors under the periosteum and performing a minimal retraction to avoid excessive stretching to the GON. Furthermore, incision for retrosigmoid approaches should be as lateral as possible (depend of the location of the sigmoid sinus) and not too caudal. Finally, avoiding extreme patient positioning reduce the risk of GON stretching in all approaches.

\section{Abbreviations}


EOP

External Occipital Protuberance

GON

Greater Occipital Nerve

IHS

International Headach Society

OA

Occipital Artery

\section{Declarations}

The work described has not been published before and it is not under consideration for publication anywhere else. Its publication has been approved by all co-authors, as well as by the responsible authorities at the institute where the work has been carried out.

\section{Acknowledgment}

The authors sincerely thank those who donated their bodies to science so that anatomical research could be performed. Results from such research can potentially increase mankind's overall knowledge that can then improve patient care. Therefore, these donors and their families deserve our highest gratitude.

Amaury Lainé for grammar and spelling check.

All the laboratory staff members for their permanent work in the anatomical department of the Bordeaux University.

\section{Funding}

The authors did not receive support from any organization for the submitted work.

\section{Conflicts of interest/Competing interests}

All authors certify that they have no affiliations with or involvement in any organization or entity with any financial interest or non-financial interest in the subject matter or materials discussed in this manuscript.

\section{Availability of data and material (data transparency)}

G. Lainé had full access to all the data in the study and takes responsibility for the integrity of the data and the accuracy of the data analysis. Data are available on request to the corresponding author.

\section{Code availability}

Not applicable

\section{Authors' contributions}


All authors contributed to the study conception and design. Material preparation, data collection and analysis were performed by G Lainé, D Liguoro. The first draft of the manuscript was written by G Lainé and all authors commented on previous versions of the manuscript. All authors read and approved the final manuscript.

Ethics approval (include appropriate approvals or waivers)

Given the documents at its disposal, the Research Ethics Committee of Bordeaux issued a favorable opinion for the publication of this research (GP-CE2021-18)

\section{Consent to participate}

Not applicable

\section{Consent for publication}

Not applicable

\section{References}

1. Cohen-Gadol A, Kemp III W, Tubbs Rs (2011) The innervation of the scalp: A comprehensive review including anatomy, pathology, and neurosurgical correlates. Surg Neurol Int 2(1):178

2. Tubbs RS, Salter EG, Wellons JC, Blount JP, Oakes WJ (2007) Landmarks for the identification of the cutaneous nerves of the occiput and nuchal regions: Nerves of Occiput and Nuchal Regions. Clin Anat 20(3):235-8

3. Bogduk N (1982) The clinical anatomy of the cervical dorsal rami. Spine (Phila Pa 1976) 7(4):319-30

4. Vital JM, Grenier F, Dautheribes M, Baspeyre H, Lavignolle B, Sénégas J (1989) An anatomic and dynamic study of the greater occipital nerve (n. of Arnold): Applications to the treatment of Arnold's neuralgia. Surg Radiol Anat 11(3):205-10

5. El Sekily NM, Zedan IH (2015) Surgical anatomy of greater occipital nerve and its relation to occipital artery. Alexandria Journal of Medicine 51(3):199-206

6. Cesmebasi A, Muhleman MA, Hulsberg P, Gielecki J, Matusz P, Tubbs RS, et al (2015) Occipital neuralgia: Anatomic considerations: Occipital Neuralgia. Clin Anat 28(1):101-8

7. McKinney P, Gottlieb J (1985) The relationship of the great auricular nerve to the superficial musculoaponeurotic system. Ann Plast Surg 14(4):310-4

8. Ducic I, Moriarty M, Al-Attar A (2009) Anatomical Variations of the Occipital Nerves: Implications for the Treatment of Chronic Headaches: Plastic and Reconstructive Surgery 123(3):859-63

9. Tubbs RS, Watanabe K, Loukas M, Cohen-Gadol AA (2014) The Intramuscular Course of the Greater Occipital Nerve: Novel Findings with Potential Implications for Operative Interventions and Occipital Neuralgia. Surgical Neurology International. 4 
10. Bovim G, Bonamico L, Fredriksen TA, Lindboe CF, Stolt-Nielsen A, Sjaastad O (1991) Topographic variations in the peripheral course of the greater occipital nerve. Autopsy study with clinical correlations. Spine (Phila Pa 1976) 16(4):475-8

11. Mosser SW, Guyuron B, Janis JE, Rohrich RJ (2004) The Anatomy of the Greater Occipital Nerve: Implications for the Etiology of Migraine Headaches: Plastic and Reconstructive Surgery 113(2):6937

12. Becser N, Bovim G, Sjaastad O (1998) Extracranial nerves in the posterior part of the head. Anatomic variations and their possible clinical significance. Spine (Phila Pa 1976) 1;23(13):1435-41

13. Janis JE, Hatef DA, Ducic I, Reece EM, Hamawy AH, Becker S, et al (2010) The Anatomy of the Greater Occipital Nerve: Part II. Compression Point Topography: Plastic and Reconstructive Surgery 126(5):1563-72

14. Won H-J, Ji H-J, Song JK, Kim Y-D, Won H-S (2018) Topographical study of the trapezius muscle, greater occipital nerve, and occipital artery for facilitating blockade of the greater occipital nerve. Fritz J, éditeur. PLoS ONE 13(8):e0202448

15. Tubbs RS, Mortazavi MM, Loukas M, D’Antoni AV, Shoja MM, Chern JJ, et al (2011) Anatomical study of the third occipital nerve and its potential role in occipital headache/neck pain following midline dissections of the craniocervical junction: Laboratory investigation. SPI 15(1):71-5

16. Headache Classification Subcommittee of the International Headache Society (2004) The International Classification of Headache Disorders: 2nd edition. Cephalalgia 24 Suppl 1:9-160

17. Taylor JL, McCloskey DI (1988) Proprioception in the neck. Exp Brain Res 70(2):351-60

18. Baron EP, Cherian N, Tepper SJ (2011) Role of greater occipital nerve blocks and trigger point injections for patients with dizziness and headache Neurologist 17:312317

19. Giliberto G, Lanzino DJ, Diehn FE, Factor D, Flemming KD, Lanzino G (2010) Brainstem cavernous malformations: anatomical, clinical, and surgical considerations. FOC 29(3):E9

20. Ducic I, Felder III JM, Endara M (2012) Postoperative Headache Following Acoustic Neuroma Resection: Occipital Nerve Injuries Are Associated With a Treatable Occipital Neuralgia. Headache: The Journal of Head and Face Pain 52(7):1136-45

21. Schankin C, Gall C, Straube A (2009) Headache Syndromes After Acoustic Neuroma Surgery and Their Implications for Quality of Life. Cephalalgia 29(7):760-71

22. Levo H, Blomstedt G, Hirvonen T, Pyykko I (2001) Causes of persistent postoperative headache after surgery for vestibular schwannoma. Clin Otolaryngol 26(5):401-6

23. Ryzenman JM, Pensak ML, Tew JM (2005) Headache: A Quality of Life Analysis in a Cohort of 1,657 Patients Undergoing Acoustic Neuroma Surgery, Results from the Acoustic Neuroma Association. The Laryngoscope 115(4):703-11

24. Mooij JJA (2009) How to Perform Posterior Fossa Approaches. In: Sindou M, Practical Handbook of Neurosurgery [Internet]. Vienna: Springer Vienna; p. 213-31. Disponible sur: http://link.springer.com/10.1007/978-3-211-84820-3_14 
25. Sindou M, Mertens P (1994) Posterior Fossa Approaches with Preservation of the Sensory Occipital Nerves: Microsurgical Anatomy and Surgical Implications. In:Karger (ed), Skull base surgery, anatomy, diagnosis and treatment pp 719-723

26. Schessel DA, Nedzelski JM, Rowed D, Feghali JG (1992) Pain after Surgery for Acoustic Neuroma. Otolaryngol Head Neck Surg 107(3):424-9

27. Kemp WJ, Cohen-Gadol AA (2011) A review of skin incisions and scalp flaps for the retromastoid approach and description of an alternative technique. Surg Neurol Int 2:143

28. Aihara N, Yamada H, Takahashi M, Inagaki A, Murakami S, Mase M (2017) Postoperative Headache after Undergoing Acoustic Neuroma Surgery via the Retrosigmoid Approach. Neurol Med Chir (Tokyo) 57(12):634-40

29. Silverman DA, Lee JH (2004) Technical Modifications of Suboccipital Craniectomy for Prevention of Postoperative Headache. Skull base 14(2):8

30. Miller CG, van Loveren HR, Keller JT, Pensak M, el-Kalliny M, Tew JM Jr (1993) Transpetrosal approach: surgical anatomy and technique. Neurosurgery 33(3):461-9

31. Pogoda L, Nijdam JS, Smeeing DPJ, Voormolen EHJ, Ziylan F, Thomeer HGXM (2021) Postoperative headache after surgical treatment of cerebellopontine angle tumors: a systematic review. Eur Arch Otorhinolaryngol.

32. Keller J.T., Saunders M.C., Beduk A. et al (1985) Innervation of the posterior fossa dura of the cat. Brain Res. Bull. 14, 97-102.

\section{Tables}


Table 1

Characteristics concerning the GON course

\begin{tabular}{|c|c|c|c|c|}
\hline & \multicolumn{2}{|l|}{ Specimen 1} & \multicolumn{2}{|l|}{ Specimen 2} \\
\hline & Left GON & Right GON & Left GON & Right GON \\
\hline $\begin{array}{l}\text { Distance from midline at the } \\
\text { exit of the intervertebral space }\end{array}$ & $18 \mathrm{~mm}$ & $18 \mathrm{~mm}$ & $17 \mathrm{~mm}$ & $19 \mathrm{~mm}$ \\
\hline Obliquus capitis inferior & $\begin{array}{l}\text { Goes around } \\
\text { the muscle }\end{array}$ & $\begin{array}{l}\text { Goes around } \\
\text { the muscle }\end{array}$ & $\begin{array}{l}\text { Goes around } \\
\text { the muscle }\end{array}$ & $\begin{array}{l}\text { Goes around } \\
\text { the muscle }\end{array}$ \\
\hline $\begin{array}{l}\text { Semi spinalis } \\
\text { capitis }\end{array}$ & $\begin{array}{l}\text { Passes } \\
\text { through the } \\
\text { muscle }\end{array}$ & $\begin{array}{l}\text { Passes } \\
\text { through the } \\
\text { muscle }\end{array}$ & $\begin{array}{l}\text { Passes through } \\
\text { the muscle }\end{array}$ & $\begin{array}{l}\text { Passes } \\
\text { through the } \\
\text { muscle }\end{array}$ \\
\hline Trapezius & $\begin{array}{l}\text { Passes } \\
\text { through the } \\
\text { muscle }\end{array}$ & $\begin{array}{l}\text { Passes } \\
\text { through the } \\
\text { muscle }\end{array}$ & $\begin{array}{l}\text { Passes through } \\
\text { its aponeurosis }\end{array}$ & $\begin{array}{l}\text { Passes } \\
\text { through the } \\
\text { muscle }\end{array}$ \\
\hline $\begin{array}{l}\text { Emergence at the superficial } \\
\text { part of the trapezius }\end{array}$ & $\begin{array}{l}\text { Laterally: } \\
17 \mathrm{~mm} \\
\text { Caudally to } \\
\text { EOP: } 15 \mathrm{~mm}\end{array}$ & $\begin{array}{l}\text { Laterally: } \\
21 \mathrm{~mm} \\
\text { Caudally to } \\
\text { EOP: } 16 \mathrm{~mm}\end{array}$ & $\begin{array}{l}\text { Laterally: } \\
26 \mathrm{~mm} \\
\text { Caudally to } \\
\text { EOP: } 21 \mathrm{~mm}\end{array}$ & $\begin{array}{l}\text { Laterraly: } \\
27 \mathrm{~mm} \\
\text { Caudally to } \\
\text { EOP: } 20 \mathrm{~mm}\end{array}$ \\
\hline Terminal branches & Various & Various & Various & Various \\
\hline
\end{tabular}

GON: Greater Occipital Nerve, EOP: External Occipital Protuberance

Table 2

Anatomical relationships between the GON and the $\mathrm{OA}$

\begin{tabular}{|c|c|c|c|c|}
\hline & \multicolumn{2}{|c|}{ Specimen 3} & \multicolumn{2}{|c|}{ Specimen 4} \\
\hline & Left & Right & Left & Right \\
\hline $\begin{array}{l}\text { Position of the GON in relation to the } \\
\mathrm{OA}\end{array}$ & Medial & Lateral & Lateral & Medial \\
\hline Intersection between GON and OA & $\begin{array}{l}\text { Single } \\
\text { point }\end{array}$ & $\begin{array}{l}\text { Single } \\
\text { point }\end{array}$ & $\begin{array}{l}\text { Single } \\
\text { point }\end{array}$ & $\begin{array}{l}\text { Helical } \\
\text { intertwining }\end{array}$ \\
\hline Common fascia & No & No & No & No \\
\hline
\end{tabular}

GON: Greater Occipital Nerve, OA: Occipital Artery 
Table 3

Risk of GON injury in posterior fossa approaches

\begin{tabular}{|lllll|}
\hline & $\begin{array}{l}\text { Midline } \\
\text { suboccipital } \\
\text { approach }\end{array}$ & $\begin{array}{l}\text { Paramedian } \\
\text { suboccipital approach }\end{array}$ & $\begin{array}{l}\text { Retrosigmoid } \\
\text { approach }\end{array}$ & $\begin{array}{l}\text { Transpetrosal } \\
\text { approach }\end{array}$ \\
\hline $\begin{array}{l}\text { Risk of direct } \\
\text { injury }\end{array}$ & No & Yes & No & No \\
\hline $\begin{array}{l}\text { Risque of } \\
\text { indirect injury }\end{array}$ & Yes & Yes & Possible & No \\
\hline
\end{tabular}

GON: Greater Occipital Nerve

Table 4

Advices to avoid GON injuries while performing posterior fossa approaches

\begin{tabular}{|c|c|c|}
\hline Approach & GON injury & Advice \\
\hline \multirow[t]{2}{*}{$\begin{array}{l}\text { Midline suboccipital } \\
\text { approach }\end{array}$} & $\begin{array}{l}\text { Direct injury } \\
:-\end{array}$ & \\
\hline & $\begin{array}{l}\text { Indirect } \\
\text { injury: + }\end{array}$ & $\begin{array}{l}\text { Place retractors under the periosteum } \\
\text { Perform a minimal retraction }\end{array}$ \\
\hline \multirow[t]{2}{*}{$\begin{array}{l}\text { Paramedian suboccipital } \\
\text { approach }\end{array}$} & $\begin{array}{l}\text { Direct injury } \\
:+\end{array}$ & Careful dissection of the subcutaneous layer \\
\hline & $\begin{array}{l}\text { Indirect } \\
\text { injury : + }\end{array}$ & $\begin{array}{l}\text { Place retractors under the periosteum } \\
\text { Perform a minimal retraction }\end{array}$ \\
\hline \multirow[t]{2}{*}{ Retrosigmoid approach } & $\begin{array}{l}\text { Direct injury } \\
:-\end{array}$ & \\
\hline & $\begin{array}{l}\text { Indirect } \\
\text { injury : +/- }\end{array}$ & $\begin{array}{l}\text { Incision as lateral as possible (depend of the position of } \\
\text { the sigmoid sinus) } \\
\text { Avoid a too caudal incision }\end{array}$ \\
\hline \multirow[t]{2}{*}{ Petrosal approach } & $\begin{array}{l}\text { Direct injury } \\
:-\end{array}$ & \\
\hline & $\begin{array}{l}\text { Indirect } \\
\text { injury :- }\end{array}$ & \\
\hline
\end{tabular}

GON: Greater Occipital Nerve

Figures 

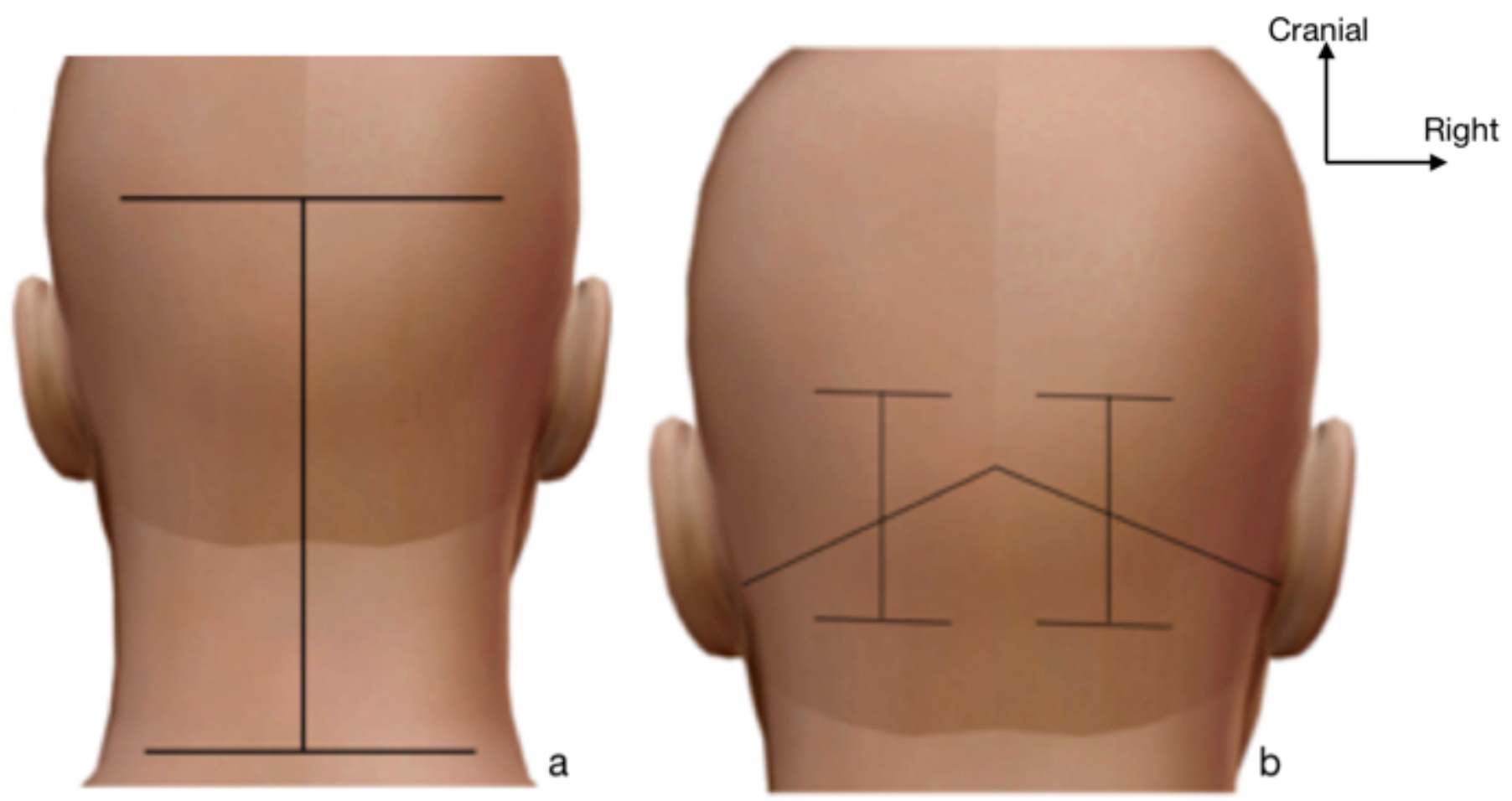

\section{Figure 1}

Schematic drawn of incisions made to study the course of the GON (1.a) and its relationships with OA (1.b), dorsal view 


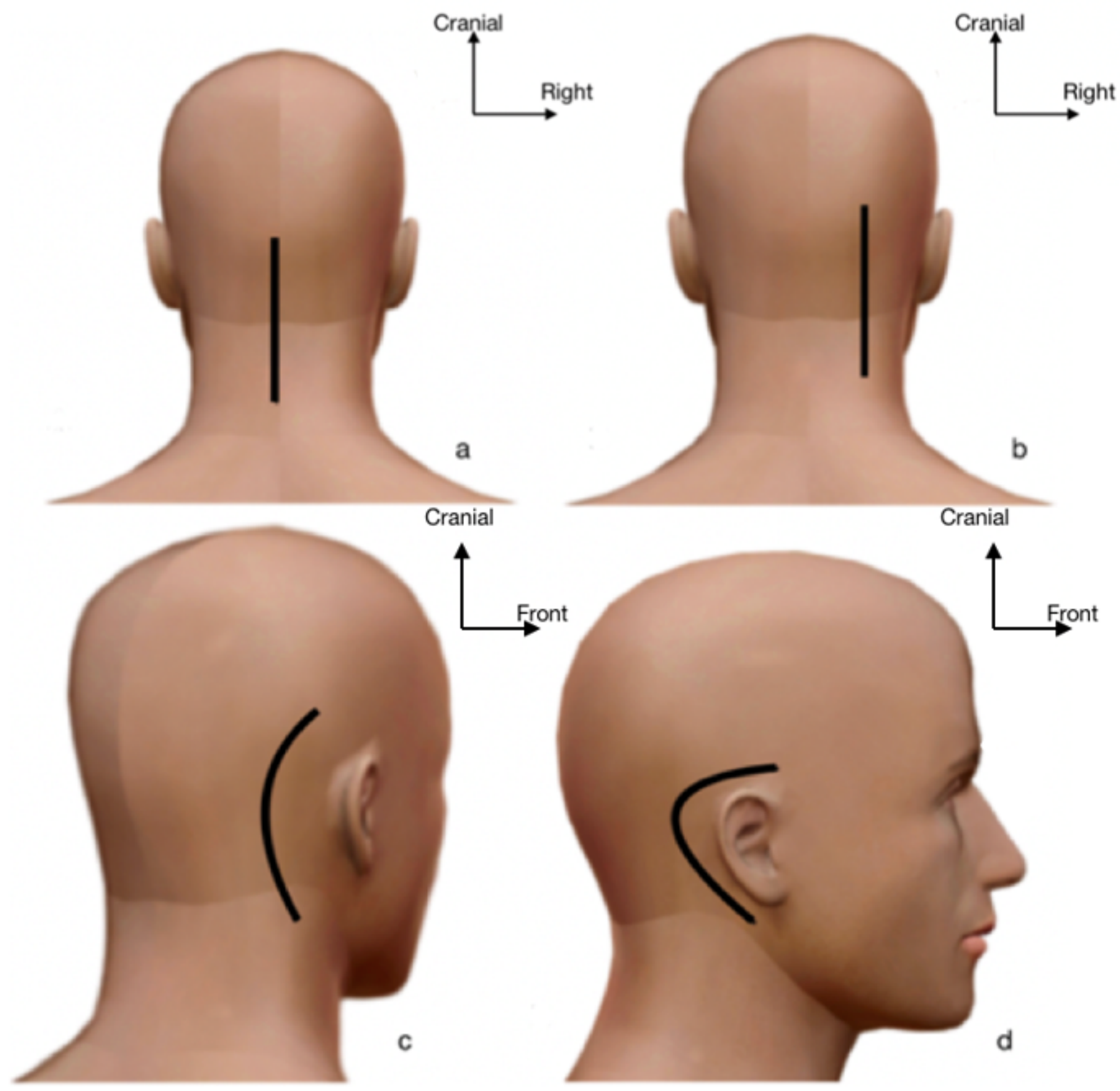

Figure 2

Schematic drawn of posterior fossa approaches studied (a: midline suboccipital approach, b: paramedian suboccipital approach, c: retrosigmoid approach, $\mathrm{d}$ : transpetrosal approach) 

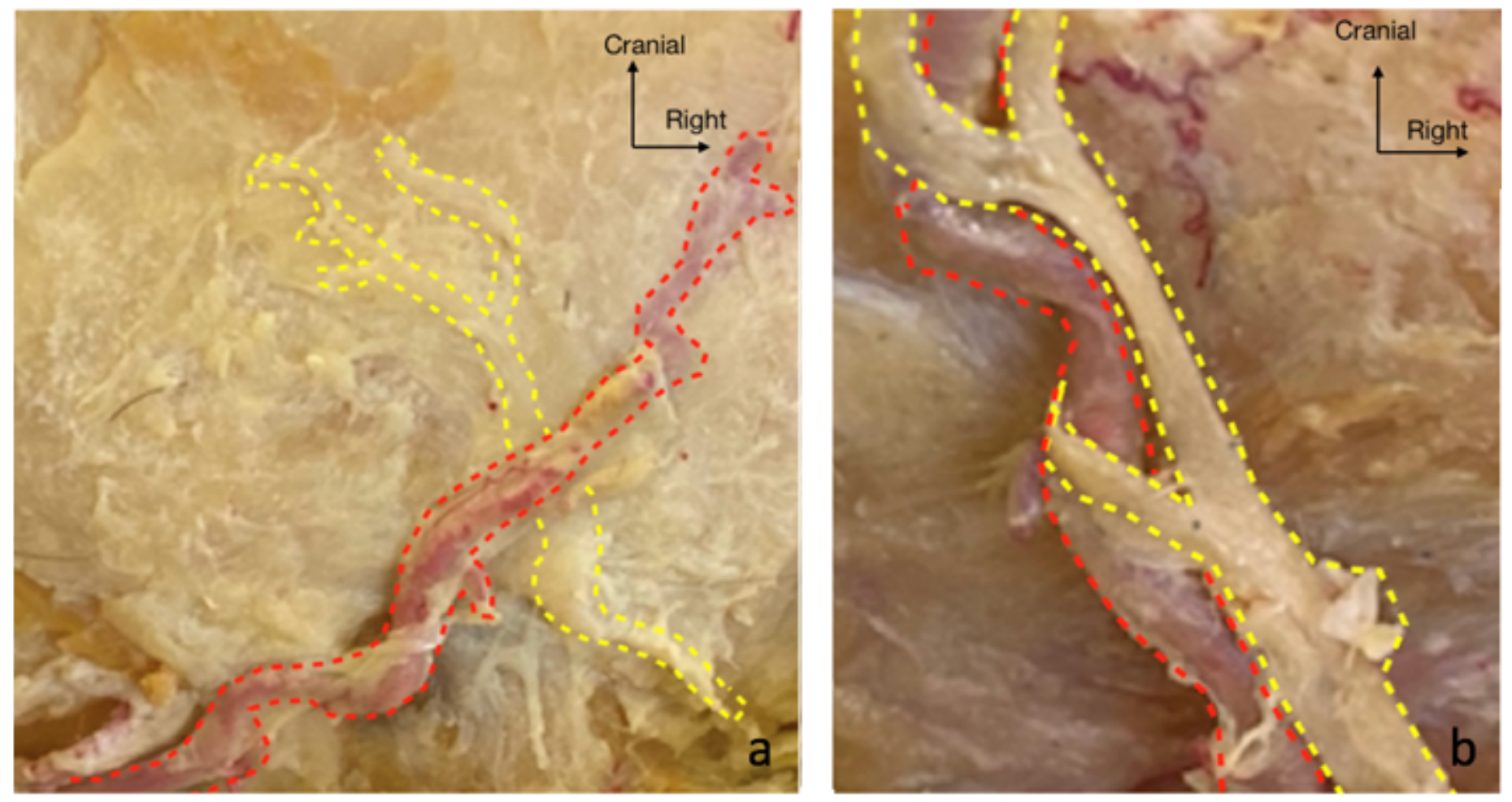

\section{Figure 3}

Course of the GON (yellow) and the OA (red) in the dorsal region of the scalp. The GON can cross the OA (fig. 3A) or travel with it (fig. 3B). 


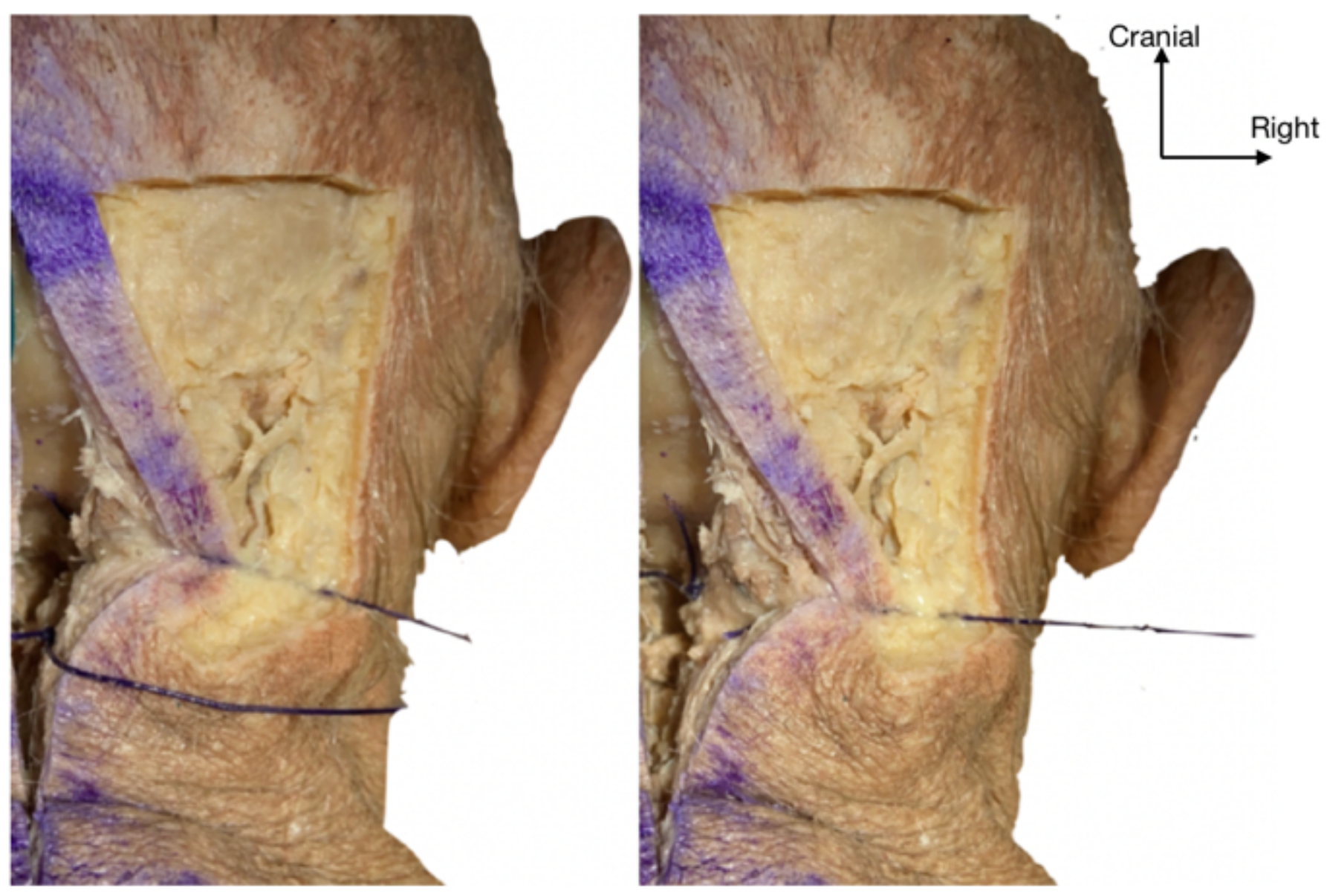

Figure 4

Traction with the threads opposite the periosteum (right) or the muscle masses (left), dorsal view. GON deformity is greater when traction is applied to the muscle 

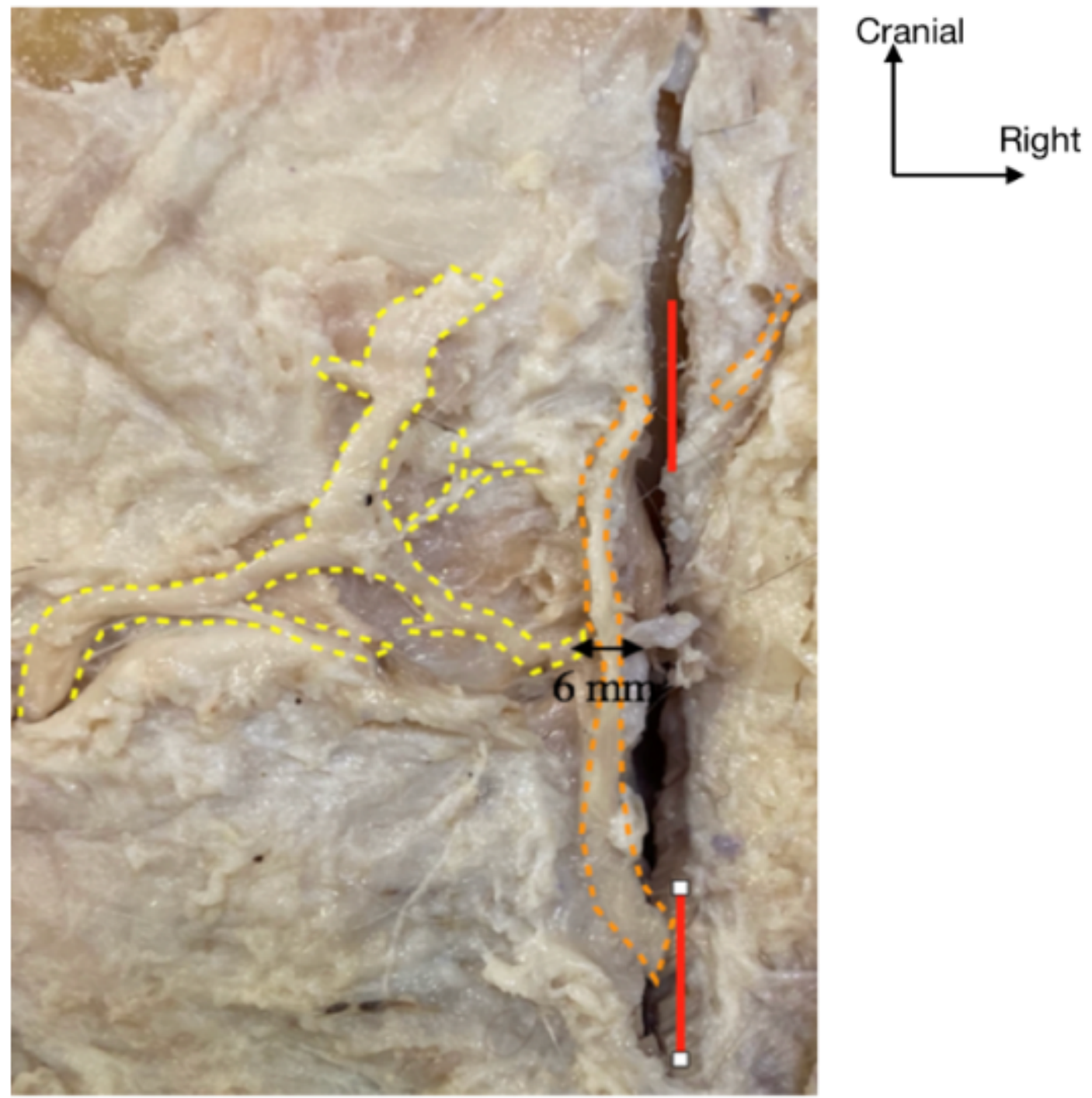

Figure 5

Paramedian suboccipital approach, dorsal view. The greater occipital nerve is shown in yellow, the lesser occipital nerve in orange. Nerve severing are marked with a red line 


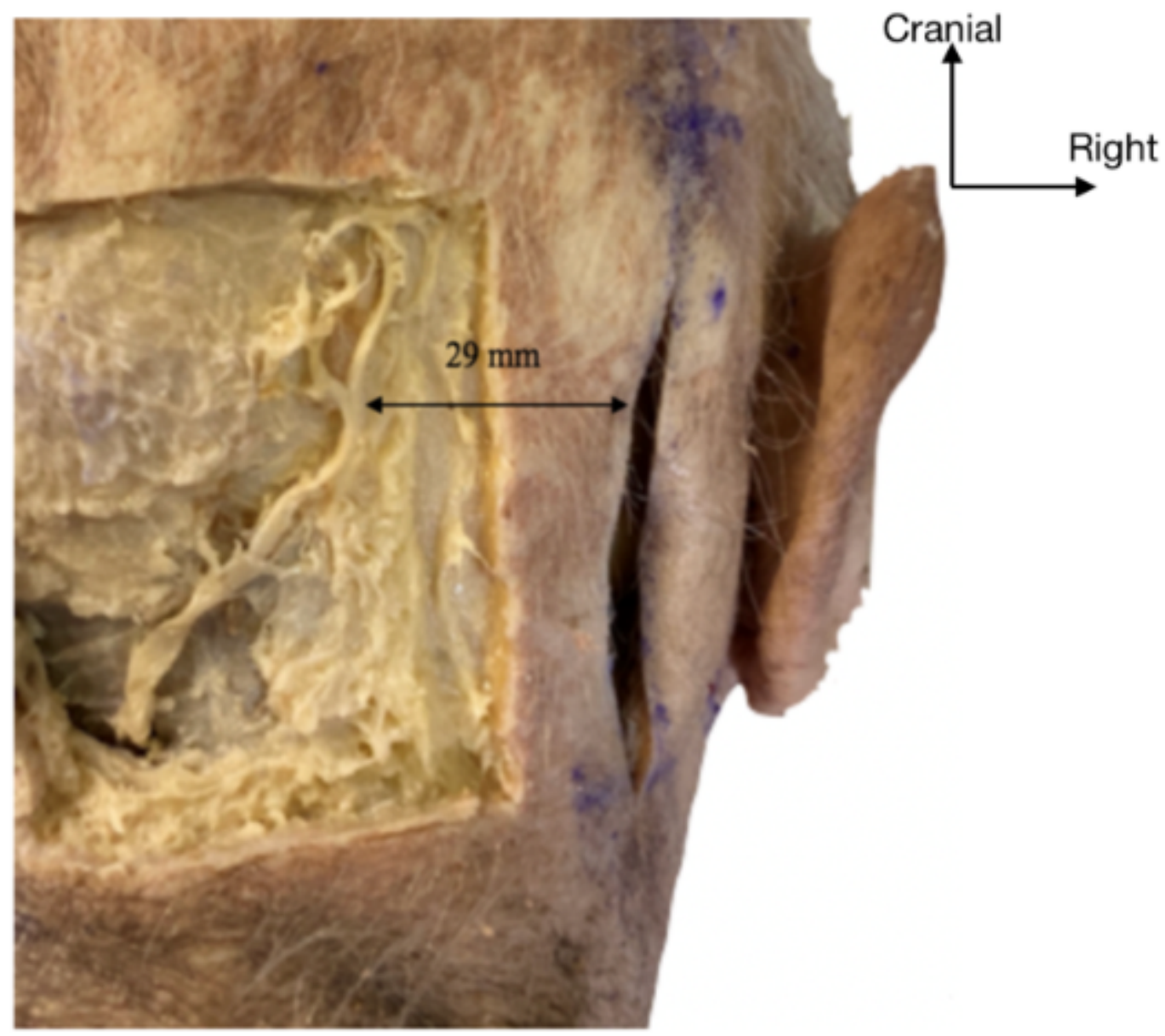

Figure 6

Minimum distance between the GON and the path of the retrosigmoid approach, dorsal view 


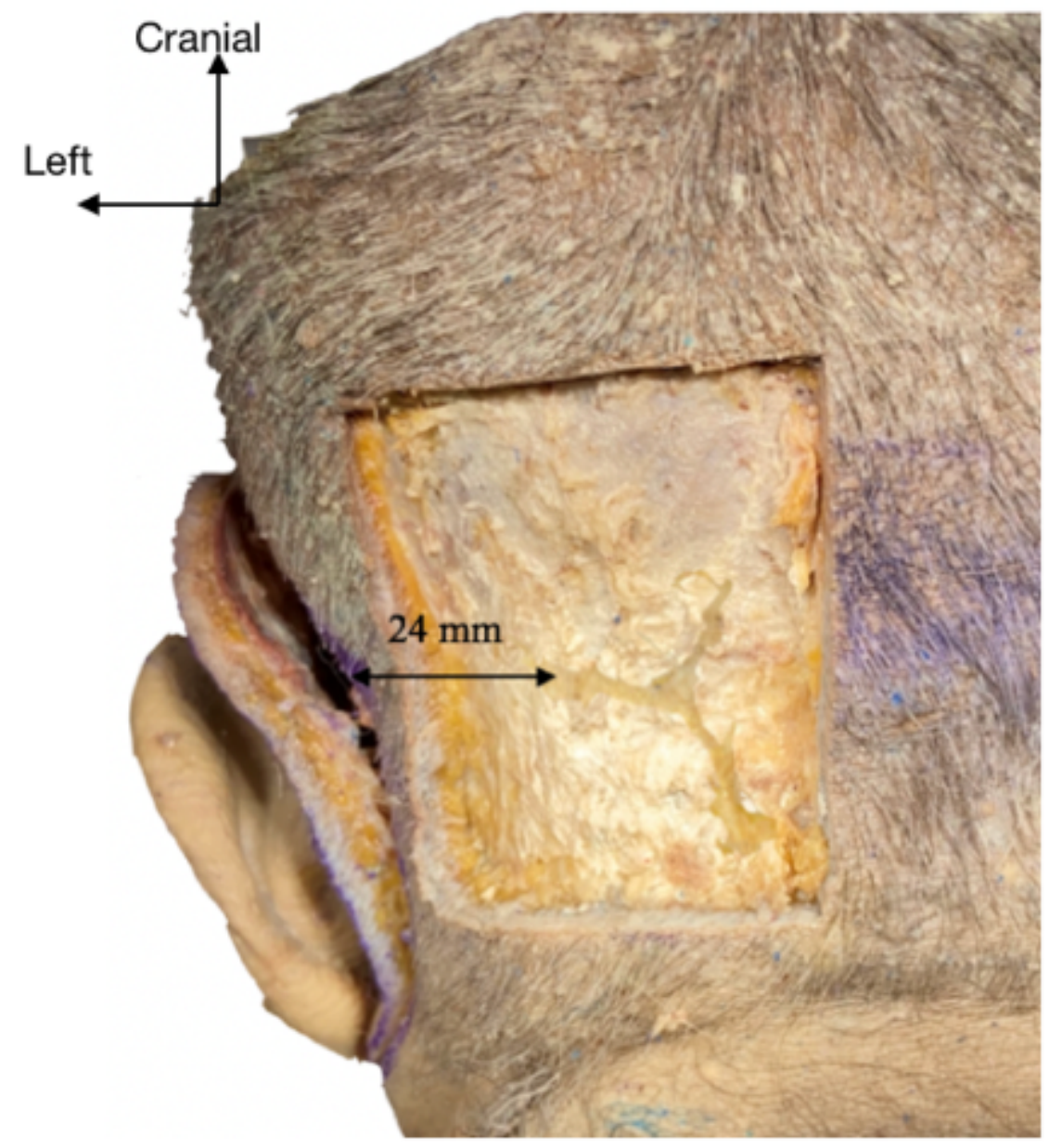

Figure 7

Minimum distance between the GON and the path of the transpetrosal approach, dorsal view 